\title{
Characterizing the Preferences and Values of US Recreational Atlantic Bluefin Tuna Anglers
}

\author{
William Morris Goldsmith \\ College of William and Mary - Virginia Institute of Marine Science \\ Andrew M. Scheld \\ Virginia Institute of Marine Science \\ John Graves \\ Virginia Institute of Marine Science
}

Follow this and additional works at: https://scholarworks.wm.edu/vimsarticles

Part of the Aquaculture and Fisheries Commons

\section{Recommended Citation}

Goldsmith, William Morris; Scheld, Andrew M.; and Graves, John, "Characterizing the Preferences and Values of US Recreational Atlantic Bluefin Tuna Anglers" (2018). VIMS Articles. 684.

https://scholarworks.wm.edu/vimsarticles/684

This Article is brought to you for free and open access by the Virginia Institute of Marine Science at W\&M ScholarWorks. It has been accepted for inclusion in VIMS Articles by an authorized administrator of W\&M ScholarWorks. For more information, please contact scholarworks@wm.edu. 


\title{
Characterizing the Preferences and Values of U.S. Recreational Atlantic Bluefin Tuna Anglers
}

\author{
William M. Goldsmith,* Andrew M. Scheld, and John E. Graves \\ Virginia Institute of Marine Science, College of William \& Mary, Post Office Box 1346, Gloucester Point, \\ Virginia 23062, USA
}

\begin{abstract}
The Atlantic Bluefin Tuna Thunnus thynnus is the target of a recreational fishery along the U.S. East Coast that is thought to be of considerable economic value. In some years, recreational landings have exceeded the sector's annual subquota due to changes in fish availability, limited predictability of angler effort, and difficulties in real-time monitoring of catch. Understanding the drivers of angler behavior is critical for predicting how effort and harvest may vary as a function of changing fish availability, regulations, or costs. To investigate angler decision making, preferences, and values, we surveyed private recreational anglers from Maine to North Carolina and employed discrete choice experiments to determine how regulatory and nonregulatory trip-specific variables influence trip-taking behavior. A latent class-ranked logit model identified two distinct classes of anglers who exhibited differing preferences in regard to the importance of nonconsumptive aspects of Bluefin Tuna fishing (e.g., catch and release). Income and recent Bluefin Tuna targeting were the primary determinants of class membership, and higher-income anglers who had targeted Bluefin Tuna in the past 5 years were significantly more likely to be in the class that derives substantive benefits from nonconsumptive angling activities. An annual consumer surplus exceeding US\$14 million was estimated for the 2015 fishery. We considered potential angler welfare impacts of possible management changes (compensating surplus) and identified a large amount of latent effort currently present in the fishery in the form of consumptiveoriented anglers. As a result, liberalization of harvest regulations could potentially lead to a large influx of effort into the fishery, which could impede the ability of managers to maintain harvest levels within prescribed limits.
\end{abstract}

Over the past several decades, resource management scholars have advocated for better integration of the social sciences into fisheries management (Voiland and Duttweiler 1984; Fenichel et al. 2013). Understanding the human component of fisheries is important for predicting how management actions will affect the well-being of fishery participants, as well as for informing the allocation of fishery resources among competing user groups (Orbach 1980). In addition, without properly understanding the preferences and motivations of anglers, predicting behavioral responses (e.g., effort and harvest) is difficult and can potentially undermine management's effectiveness and threaten a fishery's sustainability (Fulton et al. 2011; Fenichel et al. 2013; Hunt et al. 2013). Fishing behavior may, for example, change as stock status or management strategies change, and simply extrapolating past behavior under different conditions could lead to inaccurate predictions (Fulton et al. 2011). Furthermore, while determining the preferences and motivations of recreational anglers is challenging (compared with commercial fishers, who are often thought to be largely motivated by profit), understanding drivers of angler behavior for a given fishery is critical for

*Corresponding author: william.m.goldsmith@gmail.com

Received December 3, 2017; accepted March 14, 2018

This is an open access article under the terms of the Creative Commons Attribution License, which permits use, distribution and reproduction in any medium, provided the original work is properly cited. 
ensuring that the fishery's benefits are being maximized (Fedler and Ditton 1994).

The Atlantic Bluefin Tuna Thunnus thynnus supports a popular private and for-hire recreational fishery along the eastern coast of the United States from Maine to North Carolina (Marcek and Graves 2014). Of the Bluefin Tuna quota allocated to the United States by the International Commission for the Conservation of Atlantic Tunas (ICCAT), 19.7\% (195.2 metric tons for 2017) is domestically apportioned to the recreational Angling category by the National Marine Fisheries Service (NMFS), Highly Migratory Species (HMS) Management Division (NMFS 2006; NOAA 2017). This subquota is further divided among Bluefin Tuna size-classes and between the northern and southern regions of the U.S. East Coast, divided at $39^{\circ} 18^{\prime} \mathrm{N}$ latitude (Great Egg Inlet, New Jersey) in order to maintain equity in Bluefin Tuna access and landings along the coast (NOAA 2001).

The HMS Management Division uses a combination of permitting, size and bag limits, and monitoring to keep recreational Bluefin Tuna landings within the Angling category subquota. To recreationally target and harvest Bluefin Tuna and other highly migratory species (e.g., billfishes, sharks, Swordfish Xiphias gladius, and tunas), private vessel owners must obtain an annual Atlantic HMS Angling permit (NOAA 2002); as of December 31, 2015, there were 12,745 such permits issued for vessels with principal ports from Maine to North Carolina (B. McHale, NMFS, personal communication). Bluefin Tuna harvest is regulated on a trip level using size and bag limits, which the HMS Management Division reserves the right to adjust over the course of a season in order to maximize utilization of the Angling subquota and prevent overages (NOAA 2006). For example, in 2017 Angling permit holders were permitted to retain two school-size Bluefin Tuna (from 69 to $<119 \mathrm{~cm}$ curved FL [CFL]) per vessel per day, one large school (from 119 to $<150 \mathrm{~cm} \mathrm{CFL}$ ) or small medium-size (from 150 to $<185 \mathrm{~cm}$ CFL) Bluefin Tuna per vessel per day, and one large medium (from 185 to $<206 \mathrm{~cm}$ CFL) or giant-size $(\geq 206 \mathrm{~cm}$ CFL) Bluefin Tuna per vessel per year (i.e., an annual trophy) (NOAA 2017). To monitor recreational Bluefin Tuna catch and effort, NMFS administers the Large Pelagics Survey (LPS) from Maine to Virginia from June through October (Foster et al. 2008). In addition, the HMS Management Division requires Angling permit holders to report any recreational Bluefin Tuna landings or dead discards within $24 \mathrm{~h}$ of the end of the trip through the Automated Landings Reporting System (ALRS), accessed via telephone, internet, or smartphone (NOAA 2014b, 2017). Reporting via the ALRS is not required in Maryland and North Carolina, where catch-card programs exist (NMFS 2013).

Despite these strategies, managing recreational Bluefin Tuna harvest has proven challenging due to interannual variability in fish availability, limited predictability of angler effort, and difficulties in accurate monitoring of recreational landings. Estimates from the LPS become available in waves, typically a month (or longer) after the end of each wave. This lag in data availability limits the ability of the HMS Management Division to monitor the Angling category fishery in real-time to inform inseason management adjustments, which could compromise the ability to prevent landings overages for the Angling subquota (NMFS 2013; S. McLaughlin, NMFS, personal communication). In addition, the extremely low compliance of permit holders with the ALRS reporting requirement $(10-20 \%)$ has impeded its effectiveness as a real-time monitoring tool (NMFS 2013) (although the 2017 introduction of a smartphone reporting application [app] may improve compliance). As a result, significant subquota overages can occur. In 2009, for example, recreational anglers landed an estimated 566 metric tons of Bluefin Tuna-nearly three times the subquota-due to the increased availability of small medium-size Bluefin Tuna resulting from particularly strong recruitment in 2003 (NMFS 2013; ICCAT 2017). This overage occurred even though the daily retention limit for this size-class in 2009 never exceeded one fish per vessel per day (NOAA 2009). Harvest of small medium-size Bluefin Tuna was subsequently prohibited for the majority of the 2010 and 2011 fishing seasons (NOAA 2010, 2011; NMFS 2013).

Little attention has been given to how Bluefin Tuna availability, regulations, and other factors (e.g., costs) affect angler effort and fishing behavior. A better understanding of these human dimensions would decrease the likelihood of overages as the behavioral response to shifting resource conditions could be anticipated and incorporated by managers. In addition, while the economic impacts of fisheries for Bluefin Tuna and other highly migratory species have been examined (e.g., Bohnsack et al. 2002; Hutt et al. 2014), the lack of understanding of individual angler preferences and values limits the ability of the HMS Management Division to maximize the fishery's socioeconomic benefits and thus achieve optimum yield, as is required by the first National Standard of the Magnuson-Stevens Fishery Conservation and Management Act (U.S. Office of the Federal Register 2003).

Few studies have examined the factors influencing the behavior and decision making of recreational Bluefin Tuna anglers. This lack of information limits the ability of managers to anticipate shifts in fishing pressure or appropriately balance conservation measures with socioeconomic objectives. Stoll and Ditton (2006) used a contingent valuation approach to evaluate annual willingness to pay (WTP) for different management scenarios among recreational Bluefin Tuna anglers in the largely catch-and-release fishery at Hatteras, North Carolina. Those authors found, not surprisingly, that WTP was lowest in the least-flexible, catch-and-release-only regulatory 
scenario. The scope of this study was fairly limited, however, and considered the effect of only one attribute, harvest limit, on angler WTP in a single fishing location. Acknowledging a degree of complexity, Sutton and Ditton (2001) found that catch-and-release behavior in the Hatteras Bluefin Tuna fishery varied according to angler preferences and lifestyle, and additionally suggested that situational variables, such as fish size, may be important in Bluefin Tuna recreational angler decision making.

The purposes of this study were twofold. First, we aimed to improve the capacity of managers for predicting private recreational Bluefin Tuna fishing effort and harvest by evaluating the decision making and preferences of anglers. Second, we endeavored to identify the magnitude and sources of economic welfare derived from the fishery by anglers in order to inform management strategies that maximize angler benefits while maintaining landings within biologically acceptable limits. In addition, we examined the potential sources of heterogeneity acting on decision making and the derived value of the fishery by Bluefin Tuna anglers.

\section{METHODS}

We surveyed private recreational anglers permitted to target Atlantic Bluefin Tuna along the U.S. East Coast from Maine to North Carolina during the spring and early summer of 2016. The survey consisted of two main parts: (1) a sequence of stated-choice questions regarding hypothetical fishing trips to investigate decision making, preferences, and tradeoffs, and to identify individual angler benefits; and (2) a series of direct questions regarding angling behavior, attitudes, and demographics.

Survey design and delivery. - In stated-choice surveys, individuals are presented with hypothetical, multi-attribute alternatives (i.e., fishing trips) and asked to rank or choose their most preferred. Responses can be used to analyze decision making, identify tradeoffs, and evaluate preferencestasks otherwise difficult or impossible for nonmarket goods (Hanley et al. 1998; Louviere et al. 2000; Freeman 2003). As the angling experience is, in many instances, a nonmarket good, these methods have found frequent use in analyses that seek to identify value and understand behavior in recreational fisheries. Typically, these studies evaluate preferences and policy options by offering respondents choice alternatives consisting of regulatory variables (e.g., size and bag limits, seasons), catch characteristics and fishery outcomes (e.g., size and number of fish caught), and, in many cases, cost (Aas et al. 2000; Oh et al. 2005; Carter and Liese 2012; Lew and Larson 2012). Respondent decisions can be used to quantify, for example, angler WTP for kept versus released fish (Carter and Liese 2012), distinct values that may be confounded using other, simpler methods.

Discrete choice experiments (DCEs), a type of statedchoice survey in which respondents are asked to select their most preferred alternative, were used in this study. Regulatory and nonregulatory attributes and attribute levels for DCEs that covered a realistic range of harvest regulations, fishery outcomes, and costs were determined in consultation with HMS Management Division staff and recreational Bluefin Tuna anglers. Given the complex regulatory nature of the fishery (multiple size-classes, each with its own harvest limits) and our interest in nonconsumptive aspects of Bluefin Tuna fishing (such as hooking and losing fish), a total of eight attributes were identified for this study: three regulatory attributes, four catchrelated attributes, and a trip cost attribute (Table 1). Prior to survey implementation, focus groups with HMS Angling category permit holders were held in Hyannis, Massachusetts, and Toms River, New Jersey, in January and February 2016, respectively, to review draft survey materials and provide feedback regarding attributes and levels and the overall clarity of the questionnaire.

Discrete choice experiments frequently consist of two multi-attribute alternatives as well as a third "opt-out" or, in this case, "no trip" alternative (Hanley et al. 1998; Carter and Liese 2012). Respondents were asked to imagine that they could take one of two hypothetical Bluefin Tuna fishing trips described or not go Bluefin Tuna fishing at all, and to select the options that they preferred most and least, allowing for a full ranking of the three alternatives (Lew and Larson 2012). Following Carter and Liese (2012), DCEs also included a "derived" attribute, "Legal Harvest," which clarified to respondents the quantity of Bluefin Tuna of each size-class they were legally allowed to retain based on the quantity and size of fish caught and stated bag limits. Additional definition boxes on the survey pages containing DCEs further clarified the meaning of each component of the choice task (Figure 1). Macros in SAS software (SAS 9.3; SAS Institute, Cary, North Carolina),

TABLE 1. Attributes and attribute levels included in DCEs presented to recreational Bluefin Tuna anglers.

\begin{tabular}{ll}
\hline Attribute & \multicolumn{1}{c}{$\begin{array}{c}\text { Number of levels } \\
\text { (values) }\end{array}$} \\
\hline $\begin{array}{l}\text { Daily bag limit: school } \\
\text { Daily bag limit: large } \\
\text { school/small medium }\end{array}$ & $4(0,1,2,3)$ \\
$\begin{array}{l}\text { Annual bag limit: large } \\
\text { medium/giant }\end{array}$ & $4(0,1,2,3)$ \\
$\begin{array}{l}\text { Catch: school } \\
\text { Catch: large school/small } \\
\text { medium }\end{array}$ & $2(0,1)$ \\
$\begin{array}{l}\text { Catch: large medium/giant } \\
\text { Number of fish hooked } \\
\text { and lost }\end{array}$ & $3(0,1,2)$ \\
Individual trip cost & $3(0,1,2)$ \\
\hline
\end{tabular}




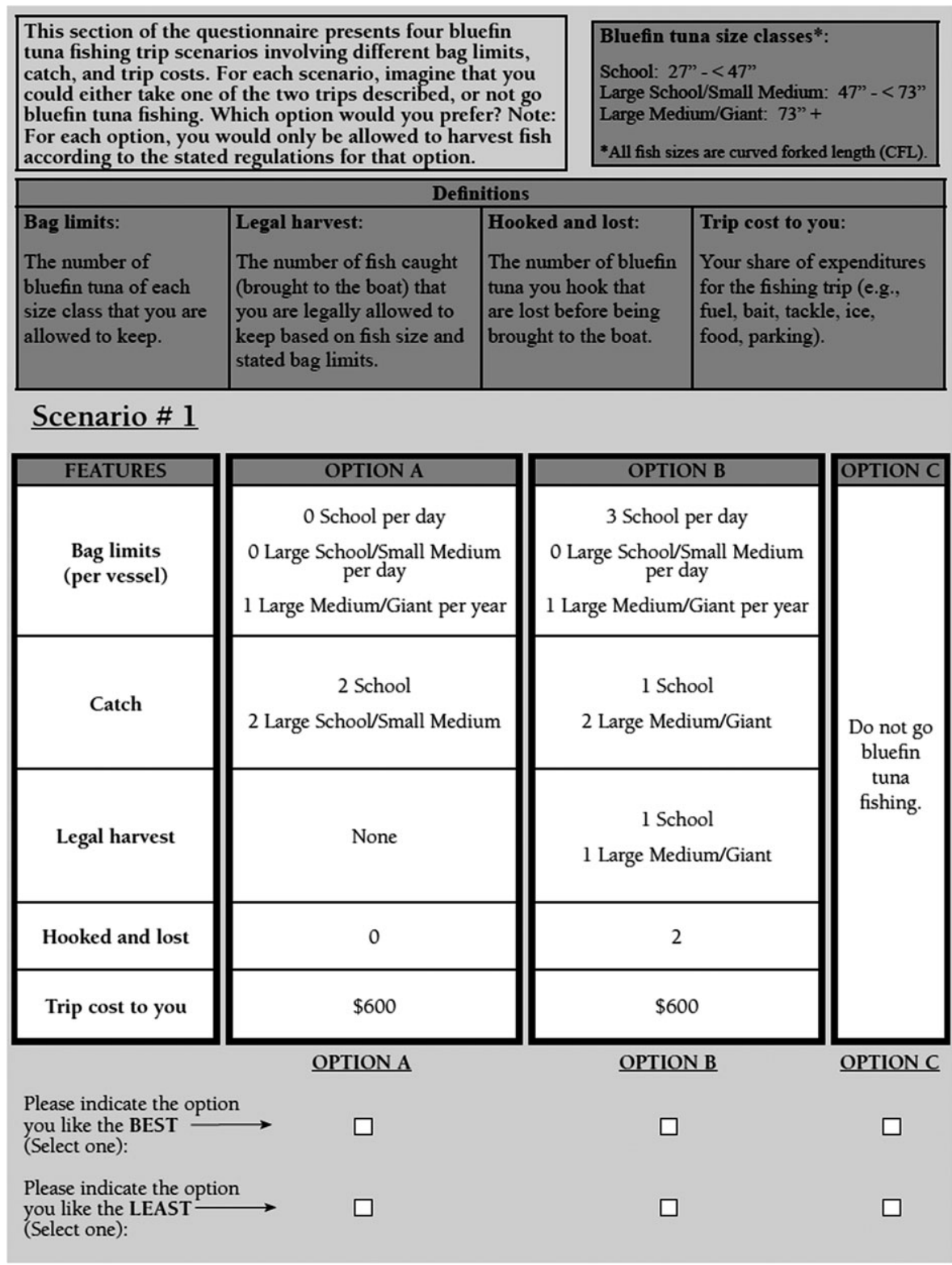

FIGURE 1. Sample DCE presented to recreational U.S. East Coast Atlantic Bluefin Tuna anglers. Since the fishery is managed using English units rather than metric units, curved fork lengths were provided in inches.

as described by Kuhfeld (2010), were used to develop an experimental design that maximized balance and orthogonality. We utilized a fractional factorial experimental design, in which a subset of the full factorial design (choice sets that include all possible combinations of attribute levels) is selected such that the effects of interest may be efficiently estimated (Louviere et al. 2000). Drawing on 144 choice alternatives, our final experimental design included 32 choice sets blocked into eight blocks of four choice sets each, a number assumed to not be cognitively burdensome and used in previous stated-choice studies of recreational anglers (Carson et al. 1994; Hanley et al. 1998; Aas et al.
2000; Hicks 2002). In addition to the four DCEs, each survey included general questions to understand how angler preferences and motivations corresponded to behavior and values as well as to address HMS Management Division interests. Questions were asked regarding demographics, primary target species, Bluefin Tuna fishing behavior and experience level, and Bluefin Tuna fishing and management preferences and attitudes.

The survey research firm QuanTech, Inc. (Rockville, Maryland), which holds a continuing agreement with NMFS to handle confidential HMS Angling permit holder information, was responsible for survey implementation 
and data collection. A stratified random sample was drawn from individuals who possessed an Angling category permit as of December 31, 2015, with a listed primary port from Maine to North Carolina (from north to south: Maine, New Hampshire, Massachusetts, Rhode Island, Connecticut, New York, New Jersey, Delaware, Maryland, Virginia, and North Carolina). Approximately $20 \%$ of Angling permit holders were selected from each state, for a total sample size of 2,600. Within each state, selected permit holders were randomly assigned one of the eight survey versions (blocks), with roughly an equal number of each survey version distributed in each state. We elected to use a mail survey since response rates for mail surveys tend to be higher than or equal to those for internet surveys (Manfreda et al. 2008; Shih and Fan 2008; Olsen 2009), and because a mixed-mode (mail and internet) economic impact survey of HMS Angling permit holders from Maine to North Carolina by Hutt et al. (2014) received nearly twice as many responses via mail. Survey delivery occurred during AprilJune 2016 and followed a modified Dillman approach (Dillman et al. 2009), which consisted of up to four mailings: a prenotification letter, initial survey package, reminder postcard, and second questionnaire. To maximize response rates, permit holders who completed the survey were entered into a random drawing to win one of two US\$500 cash prizes, and the prenotification mailing included a sticker in the shape of a Bluefin Tuna that featured the Virginia Institute of Marine Science (VIMS) logo.

Model estimation. - Stated-choice modeling is based on random utility theory, which assumes that an individual makes decisions in a way that integrates information across choice alternatives in order to maximize an underlying utility function (Louviere and Timmermans 1990). The probability of selecting a given choice alternative can be formulated as a function of the attributes in that alternative, the attributes in the other alternatives in the choice set, and the attributes of the individual in combination with alternative-specific attributes (Train 2009). In the most straightforward random utility model, the conditional logit, the probability that individual $n$ selects alternative $i$ can be written as

$$
P_{n i}=\frac{e^{\beta x_{n i}}}{\sum_{j} e^{\beta x_{n j}}}
$$

where $x$ is a vector of the attributes, $\beta$ is a vector of parameters that reflect the utility of those attributes, and the denominator sums over all alternatives in the choice set, indexed here by $j$.

Many stated-choice studies of recreational anglers have used an extension of the conditional logit model known as the random parameters (or mixed) logit (e.g., Lew and Larson 2012), which allows for random taste variation, correlation in unobserved factors influencing utility (i.e., errors) across choices, and unrestricted substitution patterns (Train 2009). In these models, coefficients for parameters of interest vary across individuals, allowing researchers to investigate heterogeneity in preferences.

While the random parameters logit is a powerful tool for identifying heterogeneity, it is less effective in explaining the sources of heterogeneity among respondents (Boxall and Adamowicz 2002). Because a primary goal of this study was to parse out differences among Bluefin Tuna anglers that might be applicable for management purposes (i.e., to identify discrete subpopulations of anglers) (Provencher et al. 2002), we elected to use a specialized form of the random parameters logit known as the latent class (or finite mixture) logit model. The underlying theory of the latent class model is that an individual's choice behavior is affected not only by observable attributes present in the choice sets but also by unobserved (or latent) preference heterogeneity (Greene and Hensher 2003). In the latent class model, each of the $\beta$ parameters takes $M$ possible values corresponding to $M$ classes, or segments, in the population, with each class having its own distinct preferences. The model jointly estimates class membership (based on individual characteristics) and class-specific choice probabilities (based on class-specific utility parameters). In the latent class model, the probability of individual $n$ choosing alternative $i$ becomes

$$
P_{n i}=\sum_{m=1}^{M} S_{n m}\left(\frac{e^{\beta_{m} x_{n i}}}{\sum_{j} e^{\beta_{m} x_{n j}}}\right)
$$

where $\beta_{m}$ refers to the utility parameters for each class $m$, and $S_{n m}$, also called the classification function, refers to the probability that individual $n$ belongs to class $m$ (Train 2009). The latent class model has been successfully used with stated preference data to identify discrete population classes in several environmental applications, including wilderness park choice (Boxall and Adamowicz 2002), marine protected area preferences (Wallmo and Edwards 2008), and freshwater recreational angler preferences (Provencher et al. 2002; Morey et al. 2006). Such an approach requires the researcher to hypothesize the number of discrete classes into which the population separates (Boxall and Adamowicz 2002). One notable benefit of this method is that the researcher is not forced to assume an individual's (unknown) class membership; instead, a class probability can be assigned for each individual (Morey et al. 2006).

Following Lew and Larson (2012), we extended the latent class model to account for (1) the full ranking of choice alternatives, obtained by asking respondents to select their most and least preferred alternatives, and (2) the panel nature of the data (each respondent answered up to four DCEs). Using the full rank ordering of 
alternatives, as opposed to simply the most preferred alternative, increases the number of choice observations obtained for each respondent, thereby reducing the variances of parameter estimates (Chapman and Staelin 1982). Given that our choice sets had three options, the probability that an individual in class $m$ chooses alternative $i$ as most preferred and alternative $k$ as least preferred $(\mathrm{Pr}$ $[i>j>k]$ ) corresponds to the probability of choosing alternative $i$ as best among the three alternatives $(\operatorname{Pr}[i \mid i$, $j, k]$ ) multiplied by the probability of choosing alternative $j$ as best among the remaining two alternatives $(\operatorname{Pr}[j \mid j$, $k]$ ). Given the hypothesized number of classes and the assumption of independently and identically Gumbel-distributed random error terms, the probability of individual $n$ choosing alternative $i$ is

$$
\begin{aligned}
P_{n i}= & \sum_{m=1}^{M}\left(\frac{e^{\lambda_{m} Z_{n}}}{\sum_{m=1}^{M} e^{\lambda_{m} Z_{n}}}\right) \\
& {\left[\left(\frac{e^{\beta_{m} X_{i}}}{e^{\beta_{m} X_{i}}+e^{\beta_{m} X_{j}}+e^{\beta_{m} X_{k}}}\right)\left(\frac{e^{\beta_{m} X_{j}}}{e^{\beta_{m} X_{j}}+e^{\beta_{m} X_{k}}}\right)\right] . }
\end{aligned}
$$

Here, $S_{n m}$ has been further specified to be a function of $Z_{n}$, representing a vector of individual-specific characteristics hypothesized to affect class membership, and $\lambda_{m}$, the vector of parameters corresponding to those individual traits, with parameters for one class set to a value of 0 as the base case (modified from Boxall and Adamowicz 2002). Assuming independence of choices (and error terms) across the choice sets, the probability that a person makes a given sequence of choices across multiple choice sets becomes the product of individual choice probabilities for that sequence, resulting in the following log-likelihood:

$$
\begin{aligned}
\ln L= & \sum_{n=1}^{N} \ln \left(\sum_{m=1}^{M}\left(\frac{e^{\lambda_{m} Z_{n}}}{\sum_{m=1}^{M} e^{\lambda_{m} Z_{n}}}\right)\right. \\
& \left.\left\{\prod_{t=1}^{T}\left[\left(\frac{e^{\beta_{m} X_{i t}}}{e^{\beta_{m} X_{i t}}+e^{\beta_{m} X_{j t}}+e^{\beta_{m} X_{k t}}}\right)\left(\frac{e^{\beta_{m} X_{j t}}}{e^{\beta_{m} X_{j t}}+e^{\beta_{m} X_{k t}}}\right)\right]\right\}\right),
\end{aligned}
$$

where $t$ represents each of up to four choice sets answered by each respondent.

The utility of a given trip alternative (and thus the probability of selecting that trip) for members of a given class was assumed to be a linear function of the 11 attributes that characterized each trip, while an alternative-specific constant (ASC) was used to represent the utility of not going Bluefin Tuna fishing (option C), as has been done in previous choice experiments for recreational fisheries (e.g., Carter and Liese 2012; Duffield et al. 2012; Lew and Larson 2012). The probability of class membership, meanwhile, was assumed to be a function of individual-specific variables, including those relating to fishing behavior (e.g, avidity, target species), attitudes (e.g., consumptive orientation), and demographics (e.g., region, income).

Model fit for varying numbers of classes (1 [conditional logit], 2, 3, 4, and 5) and differing vectors of individual parameters was assessed using Akaike's information criterion (AIC) and the Bayesian information criterion (BIC) following previous studies (e.g., Boxall and Adamowicz 2002; Wallmo and Edwards 2008). Hypotheses regarding which individual parameters to include were informed by focus group discussions and by answers to non-DCE questions in the surveys (see Appendix). One hundred model runs were conducted for each model using the high-performance computing cluster at VIMS to ensure model convergence, which was assessed by the stability of the model's negative log-likelihood over model runs. The AIC and BIC were also used to compare latent class model fit with the standard conditional logit model. All model estimation was performed using the nonlinear minimization function (nlm) in the statistical programming software R (R Core Team 2016).

Model analysis. - Following the selection of the final model and the identification of discrete classes, the probability of an individual's membership in each class was calculated based on the classification function. This prior probability was then adjusted to account for the sequence of choices actually made by that individual, resulting in a posterior probability of class membership (see Greene 2008). To estimate the marginal effect of individual characteristics on the posterior probability of class membership for each individual $n$, the log-odds of membership in class $m$ were regressed against the vector of individual characteristics $Z$ (Bucklin and Gupta 1992; Boxall and Adamowicz 1999):

$$
\ln \left(\frac{P_{n m}}{1-P_{n m}}\right)=b_{m} Z_{n}+\varepsilon_{n m}, m=1, \ldots, M .
$$

The marginal effect of each variable on class membership was then calculated by estimating the class membership probability for dummy variable values of 0 and 1 (all individual factors in $Z_{n}$ were included as dummy variables) while holding other variables constant at the overall respondent average. Additionally, we assigned individuals to a class based on their highest posterior class probability (Bucklin and Gupta 1992; Boxall and Adamowicz 1999) and then used a combination of Student's $t$-tests (for continuous, normally distributed data), permutation tests (for heavily skewed data), and Fisher exact tests (for categorical data) to test for significant differences in individualspecific variables among classes.

Willingness to pay refers to the monetary compensation needed by an individual so that utility remains 
unchanged when a choice attribute level is changed. To calculate WTP for each class $m$ for various aspects of a Bluefin Tuna fishing trip, the parameter corresponding to the attribute of interest $a$ was divided by the negative of the cost parameter $c$ :

$$
\mathrm{WTP}_{m a}=-\frac{\beta_{m a}}{\beta_{m c}}, m=1, \ldots, M
$$

To calculate several measures of angler welfare and preferences, including marginal effects of attribute changes on trip probability, compensating surplus of regulatory changes, and consumer surplus, it was necessary to estimate attribute levels for an "average" recreational Bluefin Tuna fishing trip on the U.S. East Coast during 2015 (the most recent complete fishing year prior to survey delivery) (Table 2). Estimates of the numbers of school, large school, and small medium-size Bluefin Tuna harvested and released, as well as the number of large medium and giant-size Bluefin Tuna released, from Maine to Virginia during June-October 2015 were obtained through an online LPS query (NMFS Fisheries Statistics Division, personal communication). An estimate of the number of large medium and giant-size Bluefin Tuna retained by Angling category permit holders from Maine to Virginia during 2015 (not available through an LPS query) was obtained through a data request to the HMS Management Division (S. McLaughlin, NMFS, personal communication). Total Bluefin Tuna fishing effort by private anglers from Maine to Virginia during June-October 2015, obtained through an LPS data request, was estimated to be 16,367 vessel trips (R. Kitts-Jensen, NMFS, personal communication); harvest and release estimates for the different Bluefin Tuna size-classes were divided by the effort estimate to calculate per-trip values. Because the LPS only occurs for 6 months out of the year and does not include North Carolina, average catch and effort values used here do not fully capture the U.S. East Coast Bluefin Tuna fishery but constitute the best available data and were deemed adequate for estimating catch and effort on the average trip. Focus-group attendees suggested that roughly one-third of Bluefin Tuna hooked are lost before being caught, an estimate used to derive the average number of fish hooked and lost per trip. Lastly, we used Hutt et al.'s (2014) estimate of per Angling permit holder trip expenditures for HMS Angling category permit holders targeting Atlantic tunas in 2011 from Maine to North Carolina (\$534) as an average Bluefin Tuna trip expenditure value.

Class-specific WTP for the average trip was calculated by taking the sum of the products of 2015 average attribute levels $X$ (excluding cost) and their corresponding parameters $\beta$, subtracting the value of the ASC, and dividing by the negative of the cost parameter:
TABLE 2. Attribute levels for the "average" 2015 recreational Bluefin Tuna trip taken along the U.S. East Coast. Note: while some large medium/giant-size Bluefin Tuna were undoubtedly released by recreational anglers during 2015, the large pelagics survey (LPS) did not intercept any anglers who did so (which is not surprising given that such an event is relatively rare). As a result, while recognizing that this estimate is lower than the actual value, we included the LPS estimate of 0 here.

\begin{tabular}{ll}
\hline Bluefin Tuna trip characteristics & $\begin{array}{c}2015 \text { average } \\
\text { trip }\end{array}$ \\
\hline Daily bag limit: school & 2 \\
Daily bag limit: large school/small medium & 1 \\
Annual bag limit: large medium/giant & 1 \\
Released: school & 0.07 \\
Released: large school/small medium & 0.07 \\
Released: large medium/giant & 0 \\
Harvested: school & 0.06 \\
Harvested: large school/small medium & 0.06 \\
Harvested: large medium/giant & 0.001 \\
Number of fish hooked and lost & 0.06 \\
Individual trip cost & $\$ 534$ \\
\hline
\end{tabular}

$\mathrm{WTP}_{m 2015}=-\frac{\left(\sum_{a=1}^{A} \beta_{m a} X_{2015}\right)-\beta_{m \text { NoTrip }}}{\beta_{m c}}, m=1, \ldots, M$.

A weighted average WTP for the entire sample was estimated by summing the product of class-specific WTP and the probability of class membership across all classes (Domanski and Haefen 2010). In addition, the marginal effect of each trip attribute on the class-specific probability of taking a Bluefin Tuna fishing trip was determined by calculating each class's logit probability while holding attributes at the 2015 average levels but varying the attribute level of interest from 0 to 1 (with the exception of cost, which was changed by $\$ 100$ ); the difference in probabilities then represented the marginal effect of a one-unit increase in attribute $a$.

To determine the effect of possible management changes on the welfare of private recreational Bluefin Tuna anglers, we estimated class-specific compensating surplus under relevant plausible regulatory scenarios (Hanemann 1984; Hoyos 2010):

$$
\begin{aligned}
& \text { Compensating surplus }_{m} \\
& =-\frac{1}{\beta_{m c}}\left[\ln \left(\sum e^{\beta_{m a} X_{1}}\right)-\ln \left(\sum e^{\beta_{m a} X_{0}}\right)\right],
\end{aligned}
$$

where $X_{0}$ and $X_{1}$ represent the vector of trip attributes at the status quo (2015 average trip) and after management changes, respectively. Welfare impacts were examined for the following management changes: no harvest of large 
medium or giant-size Bluefin Tuna; no harvest of any Bluefin Tuna; and complete closure of the fishery (i.e., no permitted targeting of Bluefin Tuna).

Consumer surplus for each class for 2015 was estimated by multiplying class-specific consumer surplus per trip by the estimated number of Bluefin Tuna trips taken by that class in 2015. The estimated number of trips for members of each class was calculated by multiplying the total number of Bluefin Tuna trips taken in 2015 by the proportion of all active Bluefin Tuna fishers who were posteriorly assigned to that class (i.e., respondents who indicated having targeted Bluefin Tuna in the previous 5 years). Summing these class-specific estimates provided a consumer surplus estimate for the private recreational Bluefin Tuna fishery as a whole:

$$
\begin{aligned}
& \text { Consumer surplus } 2015 \\
& =\quad \sum_{m=1}^{M}\left[\left(P_{m \text { Active }} \times \text { TotalTrips }_{2015}\right)\right. \\
& \left.\quad\left(\mathrm{WTP}_{m 2015}-\text { TripCost }_{2015}\right)\right] .
\end{aligned}
$$

Confidence intervals $(95 \%)$ for welfare measures (WTP, compensating surplus, and consumer surplus) and marginal effects were generated using the resampling method suggested by Krinsky and Robb (1986), based on 10,000 random draws of class-specific vectors of utility parameters from a multivariate normal distribution with a mean and covariance matrix set to model estimates. Each draw was used to calculate one estimate for the measure of interest (welfare or marginal effect); following all calculations, the distribution for that measure was evaluated. This approach to calculating the distribution of welfare impacts has been used previously with logit models in an environmental valuation context (see Park et al. 1991; Domanski and Haefen 2010; Hoyos 2010; Haab et al. 2012).

\section{RESULTS}

\section{Response Rates and Non-DCE Findings}

Of the 2,485 eligible respondents in the sample frame, $1,154(46.4 \%)$ returned the survey having answered at least one question, while $980(39.4 \%)$ completed at least one DCE (Table 3). The proportion of respondents from each state who completed at least one DCE did not differ significantly from the proportion of the total sample from each state $(P>0.05)$, suggesting a lack of geographic response bias. Preliminary analysis of non-DCE survey questions suggested regional segmentation and led to the inclusion of regional dummy variables in modeling efforts, along with other demographic, attitudinal, and behavioral variables (see Appendix for a summary of responses to non-DCE questions).

\section{The Latent Class Model}

Final model specification.-While latent class models with two, three, four, and five classes were attempted, convergence was only achieved for the two-class, 31-parameter model (Table 4): 20 of 100 model runs had a negative log-likelihood of between 4,857 and 4,858, while all models with larger class structures failed to converge to a stable negative log-likelihood. The three-class model, while not fully converging, appeared to separate one of the two classes in the two-class model into two separate classes rather than identifying three novel classes, lending support to the two-class model. Model selection criteria indicated that the two-class model provided a markedly better fit to the data than did the conditional logit model $(\triangle \mathrm{AIC}=-1,728.9)$.

Parameter estimates for the final two-class model are listed in Table 5. Of the two-class models tested (each with differing individual-specific variables to inform class membership), the best-fitting model included the 12 alternative-specific attributes and six individual-specific dummy variables. Consumptive and nonconsumptive orientation dummy variables were generated based on respondents' answers to two five-point Likert scale questions included in the non-DCE portion of the survey. Respondents who selected "Agree" or "Strongly Agree" for each of the following two statements were considered consumptively oriented: "I would never target Bluefin Tuna if I were not allowed to retain fish" and "Generally speaking, I would be more satisfied with a Bluefin Tuna fishing trip if I were able to bring more fish back to the dock (e.g., I am more satisfied with a trip on which I retain three Bluefin Tuna than a trip on which I retain two Bluefin Tuna)." Respondents who selected "Disagree" or "Strongly Disagree" for each of these statements were considered nonconsumptively oriented. Dummy variables were also used to identify individuals with primary ports in either New England or New York/New Jersey, those who had targeted Bluefin Tuna in the previous 5 years, and those with an annual income of over $\$ 150,000$. The median annual income for respondents was between $\$ 100,000$ and $\$ 150,000$, with nearly $40 \%$ of respondents indicating annual income greater than $\$ 150,000$ (see Table A.1 in the Appendix). Latent class probabilities were 0.53 and 0.47 for class 1 and class 2, respectively. Of anglers posteriorly assigned to class 1 (posterior probability $>0.5$ ), $96.4 \%$ were assigned with $>80 \%$ probability $(91.8 \%$ with $>90 \%$ probability), and $97.1 \%$ of anglers posteriorly assigned to class 2 were assigned with $>80 \%$ probability $(94.3 \%$ with $>90 \%$ probability).

As expected, coefficients for harvest were positive and significant for both classes, and coefficients for cost were negative. The classes differed notably, however, in the 
TABLE 3. Sample frame and responses by state.

\begin{tabular}{lcccc}
\hline State & Permit holders & Eligible respondents & Number of responses & Response rate (\%) \\
\hline Maine & 425 & 82 & 40 & 48.8 \\
New Hampshire & 186 & 38 & 8 & 21.1 \\
Massachusetts & 2,470 & 483 & 188 & 38.9 \\
Rhode Island & 539 & 107 & 41 & 38.3 \\
Connecticut & 574 & 115 & 56 & 48.7 \\
New York & 1,822 & 327 & 110 & 33.6 \\
New Jersey & 2,713 & 538 & 224 & 41.6 \\
Delaware & 750 & 149 & 69 & 46.3 \\
Maryland & 1,044 & 208 & 72 & 34.6 \\
Virginia & 908 & 180 & 71 & 39.4 \\
North Carolina & 1,314 & 258 & 101 & 39.1 \\
Total & 12,745 & 2,485 & 980 & 39.4 \\
\hline
\end{tabular}

TABLE 4. Models fitted to angler DCE responses; CL refers to conditional logit, LCM refers to latent class model, and DNC indicates that a model failed to converge to a stable negative log-likelihood.

\begin{tabular}{lccrr}
\hline Model & Number of parameters & Log-likelihood & AIC & BIC \\
\hline CL & 12 & $-5,740.48$ & $11,504.96$ & $11,579.75$ \\
Two-class LCM & 31 & $-4,857.03$ & $9,776.06$ & $9,927.58$ \\
LCM with $>$ two classes & $31+19 \times M$ & DNC & DNC & DNC \\
\hline
\end{tabular}

effect of the catch on utility. Because the model included both a catch variable and a harvest variable for each Bluefin Tuna size-class, catch parameters might be considered to represent the utility of catching and releasing a Bluefin Tuna (i.e., the model parameter identified the effect of an increase in catch independent of changes in harvest). Catch and release of Bluefin Tuna generally increased utility (and thus probability of trip choice) for class 1, but had the opposite effect on class 2 for large school/small medium and large medium/giant-size Bluefin Tuna. In addition, the no-trip ASC for class 1 was negative and significant, indicating a preference for Bluefin Tuna fishing regardless of trip characteristics. This result reflects the fact that all 523 respondents assigned to class 1 selected the no-trip option as their least-preferred option for at least one DCE, compared with only $24.3 \%$ of class 2 respondents. These differences resulted in a significantly higher probability of taking a Bluefin Tuna trip at average 2015 levels for class $1(0.95)$ than for class $2(0.27)$ and in varying (often opposite) marginal effects of attribute changes on trip probability-that is, how a marginal change in a trip attribute (e,g., increasing school-size Bluefin Tuna harvest from 0 to 1 ) would change the probability of an individual taking a Bluefin Tuna trip given their class membership (Table 6).

Latent class characterization.-Income and Bluefin Tuna targeting were the only two individual-specific variables to significantly influence class membership (Table 5).
The multiple linear regression on the log-odds of class membership as a function of the individual-specific parameters revealed that individuals who had an annual income of over $\$ 150,000$ and who had targeted Bluefin Tuna in the past 5 years were significantly more likely to be in class 1 (Table 7); an individual possessing both of these characteristics was $71.4 \%$ more likely to be in class 1 . The increase in class 1 probability due to both having high income and having recently targeted Bluefin Tuna is not simply the sum of the increases in class 1 probability for each characteristic because the two are weakly correlated (Spearman's rank correlation coefficient $\left[r_{s}\right]$ was 0.07 ). Fisher exact tests indicated that a significantly higher percentage of individuals posteriorly assigned to class 1 had targeted Bluefin Tuna in the past 5 years and had an annual income of over $\$ 150,000$ compared with those in class 2, while New England or New York/New Jersey residency and consumptive orientation were not significantly different between classes (Table A.2). Interestingly, a significantly higher percentage of permit holders posteriorly assigned to class 2 were from mid-Atlantic states, possibly due to the reduced proportion of mid-Atlantic permit holders who had recently targeted Bluefin Tuna compared with anglers from other regions (see Table A.1).

\section{Angler Welfare}

The WTP values show striking differences in preferences among the two classes (Table 8). Class 1 members 
TABLE 5. Parameter estimates for two-class latent class logit model fit to DCE data. A single asterisk $(*)$ denotes significance at $P=0.05$; a double asterisk $(* *)$ denotes significance at $P=0.01$. LS/SM $=$ large school/small medium, LM/G = large medium/giant.

\begin{tabular}{|c|c|c|c|c|}
\hline \multirow[b]{2}{*}{ Variables } & \multicolumn{2}{|c|}{ Class 1} & \multicolumn{2}{|c|}{ Class 2} \\
\hline & $\beta$ & SE & $\beta$ & SE \\
\hline \multicolumn{5}{|l|}{$X$ variables } \\
\hline Daily bag: S & $0.292 * *$ & 0.080 & 0.0950 & 0.058 \\
\hline $\begin{array}{l}\text { Daily bag: } \\
\text { LS/SM }\end{array}$ & $0.208 * *$ & 0.065 & -0.051 & 0.053 \\
\hline $\begin{array}{l}\text { Annual bag: } \\
\text { LM/G }\end{array}$ & $0.518^{* *}$ & 0.119 & 0.140 & 0.095 \\
\hline Catch: S & $0.230 * *$ & 0.078 & 0.092 & 0.059 \\
\hline Catch: LS/SM & $0.197 * *$ & 0.071 & $-0.202 * *$ & 0.059 \\
\hline Catch: LM/G & $0.122^{*}$ & 0.058 & $-0.121^{*}$ & 0.048 \\
\hline Legal harvest: $\mathrm{S}$ & $0.296^{* *}$ & 0.107 & $0.342^{* *}$ & 0.078 \\
\hline $\begin{array}{l}\text { Legal harvest: } \\
\text { LS/SM }\end{array}$ & $0.621 * *$ & 0.087 & $0.754 * *$ & 0.077 \\
\hline $\begin{array}{l}\text { Legal harvest: } \\
\text { LM/G }\end{array}$ & $0.581 * *$ & 0.129 & $0.602 * *$ & 0.110 \\
\hline Hooked and lost & $0.219 * *$ & 0.040 & 0.056 & 0.036 \\
\hline Trip cost & $-0.002^{* *}$ & 0.0003 & $-0.002^{* *}$ & 0.0002 \\
\hline No-trip ASC & $-2.647^{* *}$ & 0.271 & 0.223 & 0.186 \\
\hline \multicolumn{5}{|l|}{$Z$ variables } \\
\hline Consumptive & 0 & & -0.014 & 0.203 \\
\hline Nonconsumptive & 0 & & -0.195 & 0.208 \\
\hline High income & 0 & & $-0.363^{*}$ & 0.147 \\
\hline New England & 0 & & -0.086 & 0.178 \\
\hline $\begin{array}{l}\text { New York/New } \\
\text { Jersey }\end{array}$ & 0 & & -0.131 & 0.175 \\
\hline $\begin{array}{l}\text { Target Bluefin } \\
\text { Tuna }\end{array}$ & 0 & & $-0.964 * *$ & 0.195 \\
\hline Intercept & 0 & & $0.783 * *$ & 0.154 \\
\hline $\begin{array}{l}\text { Latent class } \\
\text { probability }\end{array}$ & 0.528 & & 0.472 & \\
\hline
\end{tabular}

exhibited positive WTP for catching and releasing Bluefin Tuna of all size-classes, while class 2 members were indifferent to catching and releasing school-size fish and actually indicated a negative WTP for catching and releasing larger size-classes, meaning that these individuals lose utility by practicing catch-and-release fishing (and would have to be paid in order to do so). Class 1 members exhibited a WTP of $-\$ 1,438$ for the no-trip ASC - in other words, these individuals would have to be paid over $\$ 1,400$ to not go on a Bluefin Tuna fishing trip - indicating the value placed on simply going Bluefin Tuna fishing, regardless of trip outcomes. For class 2 members, however, WTP for the no-trip ASC was not different from 0, indicating their indifference to a Bluefin Tuna trip independent of trip attributes (namely, harvest). Despite these contrasts in nonconsumptive preferences, WTP for harvest did not
TABLE 6. Marginal effects of a one-unit change in trip attribute levels on trip probability, given 2015 average Bluefin Tuna trip levels; S refers to school-size fish LS/SM refers to large school/small medium-size fish, $\mathrm{LM} / \mathrm{G}$ refers to large medium/giant-size fish, and CR refers to catch and release. A single asterisk (*) denotes a marginal probability statistically significant at a $95 \%$ confidence level based on 10,000 draws of the parameter vector; bold text denotes a significant difference in marginal probability between classes.

\begin{tabular}{lcc}
\hline Factor & Class 1 & Class 2 \\
\hline 2015 average trip probability & $\mathbf{0 . 9 5 5 *}^{*}$ & $\mathbf{0 . 2 6 6}^{*}$ \\
Marginal effects & & \\
CR, 1 S & $0.009^{*}$ & 0.018 \\
CR, 1 LS/SM & $\mathbf{0 . 0 0 8}^{*}$ & $-\mathbf{0 . 0 3 7 *}$ \\
CR, 1 LM/G & $\mathbf{0 . 0 0 5}^{*}$ & $-\mathbf{0 . 0 2 3}^{*}$ \\
Harvest, 1 S & $\mathbf{0 . 0 1 9 *}^{*}$ & $\mathbf{0 . 0 9 2}^{*}$ \\
Harvest, 1 LS/SM & $\mathbf{0 . 0 2 6}^{*}$ & $\mathbf{0 . 1 1 8}^{*}$ \\
Harvest, 1 LM/G & $\mathbf{0 . 0 2 3}^{*}$ & $\mathbf{0 . 1 0 3}^{*}$ \\
Hook and lose 1 fish & $0.009^{*}$ & 0.011 \\
\$100 increase in trip cost & $-\mathbf{0 . 0 0 9}^{*}$ & $-\mathbf{0 . 0 3 9}^{*}$ \\
\hline
\end{tabular}

TABLE 7. Output of multiple linear regression of the log-odds of posterior class 2 membership as a function of $Z$ parameters. A single asterisk (*) denotes significance at $P=0.05$; a double asterisk $(* *)$ denotes significance at $P=0.01$. Adjusted $R^{2}=0.1116 . F$-statistic $=21.5(P=$ $\left.2.2 \times 10^{-16}\right)$

\begin{tabular}{lcc}
\hline Variable & Estimate & $\begin{array}{c}\text { Marginal effect of } \\
\text { class 2 probability }\end{array}$ \\
\hline Intercept & $6.9088^{* *}$ & \\
Consumptive & -0.1075 & \\
Nonconsumptive & -0.3626 & \\
High income & $-1.7015^{* *}$ & -0.218 \\
New England & -0.1963 & \\
New York/New Jersey & -0.5864 & -0.446 \\
Target Bluefin Tuna & $-5.7609^{* *}$ & - \\
\hline
\end{tabular}

vary significantly between classes-that is, $95 \%$ CIs associated with WTP for harvest of each Bluefin Tuna size-class overlapped between the two classes. For the average 2015 trip WTP differed significantly between class $1(\$ 2,218.72)$ and class 2 (\$49.90), with an overall weighted average WTP of $\$ 1,285.11$ (Figure 2). Interestingly, for class 2 members, who were significantly less likely to have taken a Bluefin Tuna trip in the previous 5 years, WTP for the average 2015 trip (\$49.90) was much less than the average estimated cost per Angling permit holder for a 2015 Bluefin Tuna trip (\$534); this can be attributed to the low harvest levels associated with the average trip in 2015 .

Consumer surplus for the 2015 recreational Bluefin Tuna fishery as a whole, weighted by class (based on survey responses, $61.8 \%$ of active Bluefin Tuna fishers were estimated to be in class 1 and $38.2 \%$ in class 2 ), was estimated 
TABLE 8. Class-specific WTP for Bluefin Tuna trip attributes. A single asterisk $(*)$ denotes a WTP significantly different from 0 at a $95 \%$ confidence level based on 10,000 draws of the parameter vector; bold text denotes a significant difference in WTP between classes. LS/SM $=$ large school/small medium, LM/G = large medium/giant.

\begin{tabular}{|c|c|c|}
\hline Attribute & Class 1 & Class 2 \\
\hline Catch: S & $\$ 123.09 *$ & $\$ 44.11$ \\
\hline Catch: LS/SM & $\$ 104.52 *$ & $-\$ 97.04$ \\
\hline Catch: LM/G & $\$ 64.71 *$ & $-\$ 58.64$ \\
\hline Legal harvest: $\mathrm{S}$ & $\$ 160.20 *$ & $\$ 162.98^{*}$ \\
\hline Legal harvest: LS/SM & $\$ 338.46^{*}$ & $\$ 360.01^{*}$ \\
\hline Legal harvest: LM/G & $\$ 315.33^{*}$ & $\$ 288.58^{*}$ \\
\hline Hook and lose & $\$ 118.89 *$ & $\$ 26.71$ \\
\hline No trip (option C) & $-\$ 1,438.35^{*}$ & $\$ 111.50$ \\
\hline
\end{tabular}

to be $\$ 14.01$ million ( $\mathrm{SD}=\$ 3.99$ million), reflecting the difference between aggregate WTP for 16,367 average 2015 Bluefin Tuna vessel trips ( $\$ 22.75$ million) and aggregate estimated 2015 Bluefin Tuna trip expenditures ( $\$ 8.74$ million). Using Angling category landings for Bluefin Tuna in 2015 (113.1 metric tons; HMS Management Division, unpublished data) and the estimated proportion of landings taken by Angling category permit holders (69.4\%) as opposed to HMS Charter/Headboat permit holders (NMFS, Fisheries Statistics Division, personal communication), private-angler Bluefin Tuna landings in 2015 were estimated to be 78.5 metric tons, resulting in a consumer surplus of $\$ 80.98$ per pound $(\$ 178.16 / \mathrm{kg})$ of harvest. This high marginal WTP for harvest reflects the fact that for class 1 anglers, who represent over half of active Bluefin Tuna anglers, significant surplus is derived not just from harvest but from the nonconsumptive aspects of Bluefin Tuna fishing as well.

Class-specific estimates of angler-compensating surplus largely reflect the stark difference in preferences between classes (Table 9). For example, a complete fishery closure would result in a loss of over $\$ 1,700$ in welfare per trip for class 1 anglers, a result of the significant benefits that class 1 anglers derive from the fishery from aspects other than harvest (whose 2015 levels were relatively low). However, for class 2 anglers, a fishery closure would only generate a per-trip welfare loss of about $\$ 150$ given the already low harvest levels (and thus low class 2 WTP) associated with the 2015 average trip.

\section{DISCUSSION}

\section{Drivers of Class Membership}

Our results clearly demonstrate a segmentation in preferences among Bluefin Tuna anglers along the U.S. East Coast, indicating substantial heterogeneity in derived welfare among anglers while also providing key insights into

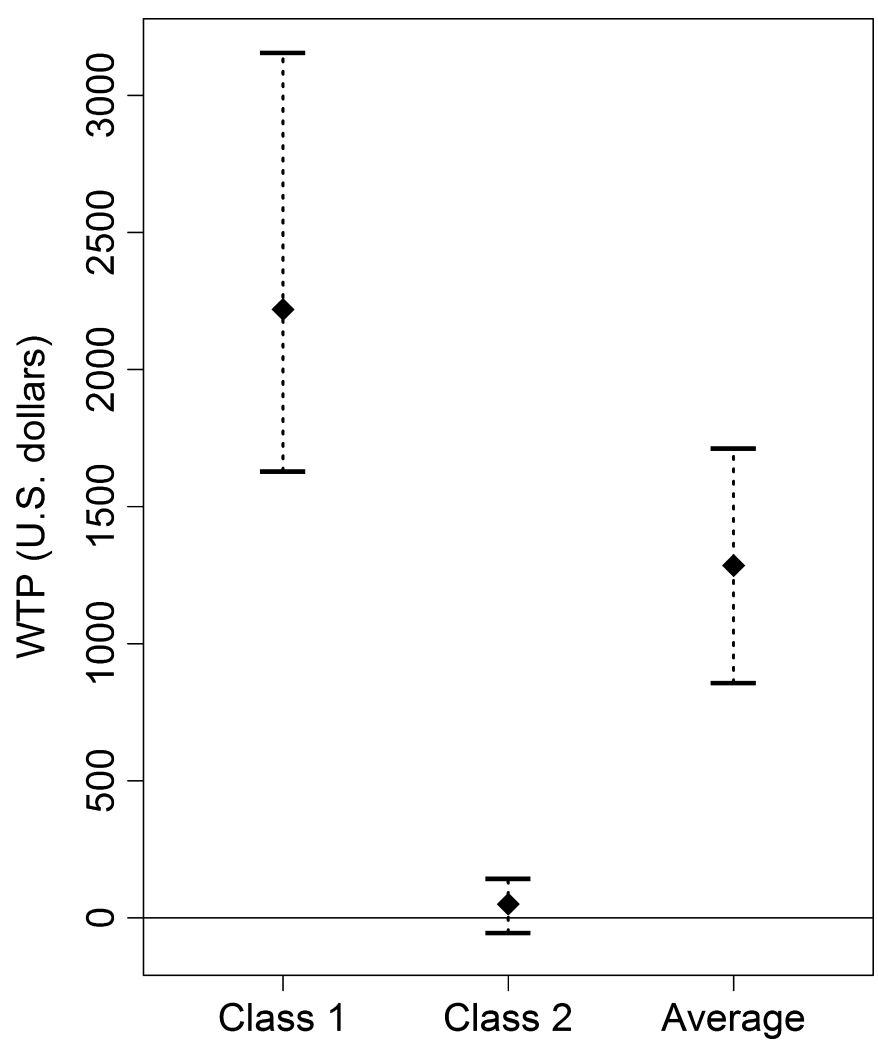

FIGURE 2. Willingness to pay (WTP) for the average 2015 Bluefin Tuna trip by class and overall. Diamonds represent the mean values and vertical dashed lines indicate the 95\% Krinsky-Robb CIs based on 10,000 random draws.

how changes to regulations and fishery conditions (e.g., costs, fish distribution) could impact effort and harvest. Preference heterogeneity appears to largely be driven by income and recent (within the past 5 years) targeting of Bluefin Tuna (or lack thereof), both of which are logical in the context of the fishery. Regulations governing recreational Bluefin Tuna harvest have generally been strict since the mid-2000s, only allowing one to three fish per vessel per day (NOAA 2012, 2014a); as a result, individuals who highly value harvest but not catch-and-release fishing (i.e., class 2 members) have perhaps not been compelled to target Bluefin Tuna in recent years - as evidenced by the 0.27 probability of taking a trip with 2015 average trip levels for class 2 members (see Table 6). This idea was reinforced during presurvey focus groups, when some anglers mentioned targeting Bluefin Tuna heavily when regulations were liberal in the early 2000s (e.g., in 2003, when vessels could retain one school, large school, or small medium-size Bluefin Tuna per person, or up to six per vessel, per day [NOAA 2003]), but subsequently switching to other species with less restrictive harvest limits when Bluefin Tuna bag limits were reduced. For lowerincome anglers, meanwhile, it may not be feasible or 
TABLE 9. Class-specific compensating surplus (base case: 2015 levels). A single asterisk $(*)$ denotes compensating surplus significantly different from 0 at a $95 \%$ confidence level based on 10,000 draws of the parameter vector; bold text denotes a significant difference in compensating surplus between classes.

\begin{tabular}{lcc}
\hline Change from 2015 fishery & Class 1 & Class 2 \\
\hline No LM-G harvest & $\mathbf{- \$ 2 6 8 . 0 0 *}$ & $\mathbf{- \$ 1 7 . 0 9}$ \\
Catch-and-release fishing only & $-\mathbf{\$ 6 7 5 . 7 6 *}$ & $\mathbf{- \$ 3 8 . 3 2}$ \\
Fishery closure & $-\mathbf{\$ 1 , 7 0 8 . 9 0 *}$ & $\mathbf{- \$ 1 4 9 . 1 4 *}$ \\
\hline
\end{tabular}

worthwhile to target Bluefin Tuna with any regularity (or at all) given the high costs of the fishery coupled with relatively restrictive harvest regulations. Among lower-income anglers (annual income $<\$ 150,000$ ) who had not targeted Bluefin Tuna in the previous 5 years, 34\% indicated the high expense of Bluefin Tuna fishing as a reason for not recently targeting the species, compared with only $20 \%$ for high-income anglers $(P=0.08)$.

The finding that anglers with higher levels of income value catch-and-release fishing more highly is supported by previous studies of U.S. recreational anglers. In a survey of freshwater anglers in New York State, Connelly et al. (2001) used cluster analysis to identify seven types of anglers; a highly skilled group that targeted coldwater species and practiced catch and release had the highest average income of the seven groups. Grambsch and Fisher (1991) found that freshwater black bass anglers with an annual income greater than the U.S. median were significantly more likely to practice catch and release than anglers with incomes below the median. Most notably, in a study of billfish tournament anglers along the U.S. Atlantic and Gulf coasts as well as in Puerto Rico, Graefe and Ditton (1997) found that income was a significant predictor of whether an angler would release all billfish (anglers with a higher income were more likely to release all billfish) and that income was the strongest predictor of the number of billfish kept (anglers with a lower income kept more billfish). While Bluefin Tuna are a more sought-after food fish than billfish, a similar association with income and catch-and-release angling could presumably hold. In the present study, a Fisher exact test revealed that a significantly higher proportion of anglers with an annual income of over $\$ 150,000$ stated that they voluntarily release Bluefin Tuna $(59 \%)$ compared with anglers with an annual income of less than $\$ 150,000$ $(42 \% ; P=0.03)$.

The relatively high value attached to catch-and-release fishing among higher-income anglers identified both in previous studies and through some of our questions may explain the continued avidity of this group despite increasingly restrictive Bluefin Tuna harvest regulations, suggesting there is a relatively inelastic response in effort to management strategies by class 1 anglers. Interestingly, our model did not identify significant differences in WTP for harvest between class 1 and class 2-both groups considered harvest equally important. However, the additional value attached by class 1 anglers to nonconsumptive aspects of Bluefin Tuna fishing (catch and release, hooking and losing fish, and other factors captured by the ASC) appear to provide sufficient incentive for this group to continue targeting Bluefin Tuna despite restrictive harvest regulations. Studies using pop-up satellite archival tags have indicated that postrelease mortality of Bluefin Tuna released in recreational fisheries is low $(<5 \%)$ across size-classes (Stokesbury et al. 2011; Marcek and Graves 2014; Goldsmith et al. 2017), suggesting that catch-and-release angling is a viable conservation strategy that would provide substantial benefits, especially to high-income anglers.

For both angler classes, WTP to harvest a large school or small medium-size Bluefin Tuna was higher than WTP to harvest a large medium or giant-size Bluefin Tuna, although differences in WTP for harvest did not differ significantly across size-classes for either angler class. This counterintuitive finding (higher WTP for harvesting a smaller fish) could be explained by the fact that in the survey, as in recent years, vessel bag limits for harvest of school and large school and small medium-size Bluefin Tuna were on a per-trip basis, whereas for large medium and giant-size Bluefin Tuna, vessel bag limits were on a per-year basis. As a result, if the annual bag limit for large medium or giant-size Bluefin Tuna is one fish, choosing to retain a large medium or giant-size Bluefin Tuna would prevent harvest of similarly sized fish on future trips. However, retaining a large school or small medium-size Bluefin Tuna would present no such constraint. A preference for both angler classes to harvest larger fish is suggested by higher mean WTP for harvesting a large school or small medium-size Bluefin Tuna than for a school-size Bluefin Tuna, both of which have bag limits on a per-trip basis.

The lack of explanatory power of the consumptive orientation variables included in the class membership model is possibly because the Likert scale questions used to define these variables were only asked to individuals who stated that they had targeted Bluefin Tuna in the previous 5 years, the latter being a dominant determinant of class membership. However, both the consumptive and nonconsumptive orientation dummy variables were highly correlated with having targeted Bluefin Tuna in the previous 5 years (Spearman's $r_{s}$ was 0.39 and 0.36 , respectively), and only the targeting variable was significant in the model, suggesting that recent Bluefin Tuna targeting behavior is likely a stronger driver of class membership. There are, however, two possible alternative reasons for the lack of significance of the consumptive orientation factors: (1) the Likert scale questions used to define 
consumptive orientation may not have adequately captured angler attitudes; and/or (2) the stated consumptive attitudes of anglers (in Likert scale questions) may not have aligned with the preferences expressed in DCE responses. This latter possibility highlights a key strength of using DCEs for eliciting preferences; for example, a respondent may not consider himself consumptively oriented when directly asked (resulting in nonconsumptive responses to Likert scale questions), but when confronted with actual trip scenarios, may in fact select trip alternatives that allow greater opportunities for harvest.

\section{WTP Comparisons with Previous Studies}

Our class-specific WTP estimates for harvest of a single Bluefin Tuna, which ranged from $\$ 160.20$ to $\$ 360.01$ across size ranges and angler classes, are generally higher than the marginal WTP for catch of an additional fish found in Johnston et al.'s (2006) meta-analysis of recreational fishing values obtained for diverse fisheries using various analytical methods (391 observations from 48 studies between 1977 and 2001), which found WTPs ranging from $\$ 0.048$ to $\$ 612.79$, with a mean of $\$ 16.82$. Species in the meta-analysis with higher WTPs $(>\$ 100 /$ fish) generally included popular food and sport fish such as salmon (e.g., Jones and Stokes Associates 1987; Morey et al. 1993) and big-game species such as billfish and sharks (e.g., Schuhmann 1996 reviewed in Johnston et al. 2006). In addition, our estimates are similar to Duffield et al.'s (2012) WTP estimate of \$276.44 for catching a Blue Marlin Makaira nigricans among private-boat Hawaiian anglers (the survey did not distinguish between harvested and released fish). Given their elite status as both a food and sport fish, the high WTP estimated for Bluefin Tuna harvest is not surprising.

Class 1 WTPs for Bluefin Tuna fishing trip characteristics were found to be generally similar to values for other sport fish for which significant nonharvest benefits are derived. For example, Duffield et al. (2012) also found that Hawaiian anglers were willing to pay $\$ 166.45$ to see a Blue Marlin and \$128.72 to hook and lose a Blue Marlin- $60 \%$ and $47 \%$ of WTP for catch, respectively. The importance of these nonconsumptive aspects, in terms of both WTP and relative importance compared with catch, is similar to class 1 members in the present study, who demonstrated a WTP of $\$ 118.89$ for hooking and losing a Bluefin Tuna-35-74\% of WTP for Bluefin Tuna harvest, depending on size-class. Similarly, in their discrete choice survey of southeastern U.S. anglers, Carter and Liese (2012) found WTP for releasing an additional King Mackerel Scomberomorus cavalla due to having reached the bag limit (\$37.62) to be nearly half the WTP for King Mackerel harvest (\$77.59), although this reflects marginal WTP for the second fish caught rather than the first fish and thus is a conservative estimate. While the WTP values for
Bluefin Tuna are higher, the relative proportion of WTP for catch-and-release fishing compared with harvest (21$77 \%$, depending on size-class) for class 1 is similar to that shown for King Mackerel. Thus, for class 1 anglers, Bluefin Tuna, in addition to being a highly desirable food fish, are also a valuable game fish that, like Blue Marlin and King Mackerel, can provide significant benefits even in the absence of catch and/or harvest.

For class 2 members, harvest is the primary factor driving choice, and preference for harvest (and aversion to practicing catch and release) is even stronger than in other studies for coveted food fish. In the same study that found relatively high WTP for King Mackerel release compared with harvest, Carter and Liese (2012) calculated a WTP for harvesting Red Snapper Lutjanus campechanus and grouper species ( $\$ 80.40$ and $\$ 62.97$, respectively) more than eight times the value of releasing the fish due to bag limit restrictions ( $\$ 9.95$ and $\$ 6.86$, respectively). While both Red Snapper and groupers are considered highly desirable food species, anglers still placed some value on catch-and-release fishing, compared with the negative WTP values exhibited by class 2 Bluefin Tuna anglers in the present study.

\section{Applications to Management}

We found that the recreational Bluefin Tuna fishery resulted in an aggregate consumer surplus of over \$14 million for 2015. This estimate reflects the total net benefits that anglers derived above and beyond trip expendituresa recreational analog to profit obtained by a commercial fishery. Because this consumer surplus estimate does not include clients on charter fishing vessels targeting Bluefin Tuna (who presumably derive benefits exceeding charter costs) and only includes effort captured by the LPS, which does not fully cover the fishery's spatial and temporal range, it is likely conservatively low. Aggregate consumer surplus estimates for recreational fisheries are generally scarce in the literature due to the lack of available expenditure and valuation information. It is worth noting that our estimate does carry significant caveats: for example, (1) the assumption that Bluefin Tuna trips in 2015 cost roughly the same as all tuna trips (Bluefin Tuna and other species) along the U.S. East Coast in 2011, and (2) the fact that the relative proportion of anglers in each class who had targeted Bluefin Tuna in the past 5 years is equivalent to the relative proportion of Bluefin Tuna trips taken by members of each class in 2015. Nevertheless, our estimate provides a reasonable starting point for comparison with previous research as well as consideration of allocation questions within the U.S. Bluefin Tuna fishery.

Using responses from a contingent valuation survey of recreational Bluefin Tuna anglers (both private and charter) in Hatteras, North Carolina, Stoll and Ditton (2006) estimated an individual annual consumer surplus of $\$ 344$ 
for maintaining the quality of the Bluefin Tuna fishery with the regulations in place at the time; because anglers averaged 0.97 trips per year, this value essentially amounted to a per-trip consumer surplus. While this value is quite different from the consumer surplus estimates generated for each class in the present study $(\$ 1,684.72$ and $-\$ 484.10$ for class 1 and class 2 , respectively), it does fall in between the two values and raises the possibility that the median estimate of $\$ 344$ may represent an aggregation of substantial heterogeneity in preferences among Bluefin Tuna anglers such as those identified here.

Perhaps of greater policy relevance than aggregate consumer surplus in the fishery is the marginal consumer surplus, estimated to be $\$ 80.98$ per pound of harvested Bluefin Tuna. When considering the allocation of a fishery's quota among competing sectors-for example, commercial and recreational-resource economists have generally relied on some version of the equimarginal principle, which dictates that an efficient allocation of the resource occurs when the marginal net benefit of additional quota is equal among sectors. In 2015, commercial ex-vessel prices (revenue) of Bluefin Tuna landed in the United States ranged from $\$ 5.75$ to $\$ 7.27 / 1 \mathrm{~b}$ ( $\$ 12.65$ $\$ 15.99 / \mathrm{kg}$ ) (NMFS 2017), meaning that marginal profit was even lower (ex-vessel price minus expenses). Based on the equimarginal principle alone, it would appear economically efficient to increase the Angling category share of the U.S. Bluefin Tuna quota. However, it is important to remember that since the probability of Class 1 anglers taking a trip was 0.96 , given 2015 average values, additional effort resulting from increased stock abundance (catchability), angling category allocation and/or liberalized regulations would likely come from the more consumptively oriented class 2 (whose probability of taking a trip, given 2015 average values, was only 0.27 ). Because class 2 consumer surplus for the average 2015 trip was $-\$ 484.10$, substantial increases in harvest (and thus allocation) would be needed to result in a positive marginal consumer surplus for class 2, while class 1 effort (and surplus) likely would not change markedly with higher harvest levels, though there would be some increase due to class 1's positive WTP for harvest. As a result, increasing allocation levels to the recreational Angling category may not significantly improve the efficiency of the U.S. Bluefin Tuna fishery as a whole.

While the model was effective at explaining the sources of heterogeneity among recreational Bluefin Tuna anglers, those sources-income and recent Bluefin Tuna targeting - do not initially appear to be as salient to management as, for example, regional heterogeneity. However, what our results do show is a large amount of latent, or potential, effort in the fishery: the class 2 anglers who have not targeted Bluefin Tuna recently, but who could plausibly reenter the fishery if conditions-fish availability, regulations, and costs - made it a worthwhile endeavor. The availability of and regulations for alternative target species, which were found to be diverse and region-specific among respondents, could also play a significant role in determining whether class 2 anglers decide to target Bluefin Tuna; for future studies, especially those on a smaller geographic scale, it may be practical to consider these species tradeoffs among anglers. With the most recent Atlantic Bluefin Tuna stock assessment indicating that the species is no longer experiencing overfishing (ICCAT 2017), managers should be wary that even a small increase in daily Bluefin Tuna bag limits could result in a large and sudden increase in participation and harvest. Their consideration of the utility function of class 2 anglers (and thus the "tipping point" at which inactive anglers could reenter the fishery) could inform the degree to which regulations should be liberalized in order to maintain landings within the designated subquota.

Our application of a latent class logit model to decisions made by recreational Bluefin Tuna anglers revealed distinct heterogeneity in preferences among anglers, with important implications for management. The use of latent class models, as opposed to more conventional randomparameters models, could prove useful in other recreational fishery scenarios where class-specific management - for example, regionally or by gear type - is a feasible strategy. Our results could also help inform, through the estimation of compensating surplus, the comparative welfare impact of management alternatives that would meet similar biological goals (though models and assumptions regarding catch, harvest, and other conditions such as resource access would be required; see Holzer and McConnell 2014). By doing so, managers could best maximize the welfare of these user groups while maintaining fishing mortality within biologically acceptable limits.

\section{ACKNOWLEDGMENTS}

The authors thank Brad McHale and Sarah McLaughlin of the NMFS Atlantic Highly Migratory Species Management Division, as well as 12 recreational Bluefin Tuna anglers who participated in focus groups, for their advice regarding survey development and their review of survey materials. In addition, we are grateful to Kristy Wallmo and Clifford Hutt (NMFS) for their experimental design and modeling guidance. We also thank QuanTech, Inc., for survey distribution and response collection and $O n$ the Water magazine for assistance with outreach to increase response rates. Rob Hicks (College of William \& Mary), Ron Salz (NMFS), and Deb Steinberg (VIMS) thoroughly reviewed a draft manuscript and provided valuable input. The survey protocol and all materials were approved by the College of William \& Mary's Protection of Human Subjects Committee (Protocol PHSC-2015-11-19-10758- 
amscheld). Support for this project was provided by NMFS Saltonstall-Kennedy Grant 15GAR020, a NMFS Sea Grant Fellowship in Marine Resource Economics (NA15OAR4170179), and by grants from the International Women's Fishing Association and the VIMS Foundation. This article is contribution number 3737 from the Virginia Institute of Marine Science, College of William \& Mary. There is no conflict of interest declared in this article.

\section{REFERENCES}

Aas, O., W. Haider, and L. Hunt. 2000. Angler responses to potential harvest regulations in a Norwegian sport fishery: a conjoint-based choice modeling approach. North American Journal of Fisheries Management 20:940-950.

Bohnsack, B. L., R. B. Ditton, J. R. Stoll, R. J. Chen, R. Novak, and L. S. Smutko. 2002. The economic impact of the recreational Bluefin Tuna fishery in Hatteras, North Carolina. North American Journal of Fisheries Management 22:165-176.

Boxall, P. C., and W. L. Adamowicz. 1999. Understanding heterogeneous preferences in random utility models: the use of latent class analysis. University of Alberta, Staff Paper 99-02, Edmonton.

Boxall, P. C., and W. L. Adamowicz. 2002. Understanding heterogeneous preferences in random utility models: a latent class approach. Environmental and Resource Economics 23:421-446.

Bucklin, R. E., and S. Gupta. 1992. Brand choice, purchase incidence, and segmentation: an integrated modeling approach. Journal of Marketing Research 29:201-215.

Carson, R. T., J. J. Louviere, D. A. Anderson, D. S. Bunch, D. A. Hensher, R. M. Johnson, W. F. Kuhfeld, D. Steinberg, J. Swait, H. Timmermans, and J. B. Wiley. 1994. Experimental analysis of choice. Marketing Letters 5:351-367.

Carter, D. W., and C. Liese. 2012. The economic value of catching and keeping or releasing saltwater sport fish in the southeast USA. North American Journal of Fisheries Management 32:613-625.

Chapman, R. G., and R. Staelin. 1982. Exploiting ranked ordered choice set data within the stochastic utility model. Journal of Marketing Research 19:288-301.

Connelly, N. A., B. A. Knuth, and T. L. Brown. 2001. An angler typology based on angler fishing preferences. Transactions of the American Fisheries Society 130:130-137.

Dillman, D. A., J. D. Smyth, and L. M. Christian. 2009. Internet, mail, and mixed-mode surveys: the tailored design method. Wiley, New York.

Domanski, A., and R. H. Von Haefen. 2010. Estimation and welfare analysis from mixed logit recreation demand models with large choice sets. North Carolina State University, working paper, Raleigh.

Duffield, J., C. Neher, S. Allen, D. Patterson, and B. Gentner. 2012. Modeling the behavior of marlin anglers in the Western Pacific. Marine Resource Economics 27:343-357.

Fedler, A. J., and R. B. Ditton. 1994. Understanding angler motivations in fisheries management. Fisheries 19(4):6-13.

Fenichel, E. P., J. K. Abbott, and B. Huang. 2013. Modelling angler behaviour as a part of the management system: synthesizing a multidisciplinary literature. Fish and Fisheries 14:137-157.

Foster, J., R. Salz, T. R. Sminkey, D. Van Voorhees, R. Andrews, and H.-L. Lai. 2008. Large pelagics survey: methodology overview and issues. ICES (International Council for the Exploration of the Sea) C.M. 2008/K:22, Copenhagen.

Freeman, A. M. III. 2003. The measurement of environmental and resource values: theory and methods. Resources for the Future, Washington, D.C.
Fulton, E. A., A. D. M. Smith, D. C. Smith, and I. E. van Putten. 2011 Human behaviour: the key source of uncertainty in fisheries management. Fish and Fisheries 12:2-17.

Goldsmith, W. M., A. M. Scheld, and J. E. Graves. 2017. Performance of a low-cost, solar-powered pop-up satellite archival tag for assessing post-release mortality of Atlantic Bluefin Tuna (Thunnus thynnus) caught in the US East Coast light-tackle recreational fishery. Animal Biotelemetry [online serial] 5:29.

Graefe, A. R., and R. B. Ditton. 1997. Understanding catch-and-release behavior among billfish anglers. Proceedings of the Gulf and Caribbean Fisheries Institute 49:430-455.

Grambsch, A. E., and W. L. Fisher. 1991. 1985 catch-and-release statistics for U.S. bass and trout anglers. Pages 390-396 in D. Guthrie, J. M. Hoenig, M. Holliday, C. M. Jones, M. J. Mills, S. A. Moberly, K. H. Pollock, and D. R. Talhelm, editors. Creel and angler surveys in fisheries management. American Fisheries Society, Symposium 12, Bethesda, Maryland.

Greene, W. H. 2008. Econometric analysis, 6th edition. Pearson Education, Upper Saddle River, New Jersey.

Greene, W. H., and D. A. Hensher. 2003. A latent class model for discrete choice analysis: contrasts with mixed logit. Transportation Research Part B 37:681-698.

Haab, T., R. Hicks, K. Schnier, and J. C. Whitehead. 2012. Angler heterogeneity and the species-specific demand for marine recreational fishing. Marine Resource Economics 27:229-251.

Hanemann, W. M. 1984. Welfare evaluations in contingent valuation experiments with discrete responses. American Journal of Agricultural Economics 66:332-341.

Hanley, N., R. E. Wright, and V. Adamowicz. 1998. Using choice experiments to value the environment. Environmental and Resource Economics 11:413-428.

Hicks, R. L. 2002. Stated preference methods for environmental management: recreational Summer Flounder angling in the northeastern United States. Final Report prepared for the National Marine Fisheries Service, Office of Science and Technology, Fisheries Statistics and Economics Division, Requisition Request NFFKS-18, Washington, D.C.

Holzer, J., and K. McConnell. 2014. Allocation without property rights. Journal of the Association of Environmental and Resource Economists 1:209-232.

Hoyos, D. 2010. The state of the art of environmental valuation with discrete choice experiments. Ecological Economics 69:1595-1603.

Hunt, L. M., S. G. Sutton, and R. Arlinghaus. 2013. Illustrating the critical role of human dimensions research for understanding and managing recreational fisheries within a social-ecological system framework. Fisheries Management and Ecology 20:111-124.

Hutt, C., S. Lovell, and G. Silva. 2014. The economic contributions of Atlantic highly migratory species anglers in New England and the Mid-Atlantic, 2011. U.S. National Marine Fisheries Service, Silver Spring, Maryland.

ICCAT (International Commission for the Conservation of Atlantic Tunas). 2017. Report of the standing committee of research and statistics (SCRS). ICCAT, SCRS, Madrid.

Johnston, R. J., M. H. Ranson, E. Y. Besedin, and E. C. Helm. 2006. What determines willingness to pay per fish? A meta-analysis of recreational fishing values. Marine Resource Economics 21:1-32.

Jones and Stokes Associates. 1987. Juneau area sport fishing economic study. Prepared by Jones \& Stokes Associates, Inc., and Robert D. Niehaus, Inc. Alaska Department of Fish and Game, Sport Fish Division, Study Report AK 99518-1599, Anchorage.

Krinsky, I., and A. L. Robb. 1986. On approximating the statistical properties of elasticities. Review of Economics and Statistics 68:715719. 
Kuhfeld, W. F. 2010. Marketing research methods in SAS: experimental design, choice, conjoint, and graphical techniques. SAS Institute, Cary, North Carolina.

Lew, D. K., and D. M. Larson. 2012. Economic values for saltwater sport fishing in Alaska: a stated preference analysis. North American Journal of Fisheries Management 32:745-759.

Louviere, J., and H. Timmermans. 1990. Stated preference and choice models applied to recreation research: a review. Leisure Sciences 12:9-32.

Louviere, J. J., D. A. Hensher, and J. D. Swait. 2000. Stated choice methods: analysis and application. Cambridge University Press, Cambridge, UK

Manfreda, K. L., M. B. Bosnjak, J. Berzelak, I. Haas, and V. Vehovar. 2008. Web surveys versus other survey modes: a meta-analysis comparing response rates. International Journal of Market Research 50:79-104.

Marcek, B. J., and J. E. Graves. 2014. An estimate of post-release mortality of school-size Bluefin Tuna in the U.S. recreational troll fishery. North American Journal of Fisheries Management 34:602-608.

Morey, E., J. Thacher, and W. Breffle. 2006. Using angler characteristics and attitudinal data to identify environmental preference classes: a latent class model. Environmental and Resource Economics 34:91115.

Morey, E. R., R. D. Rowe, and M. Watson. 1993. A repeated nestedlogit model of Atlantic Salmon fishing. American Journal of Agricultural Economics 75:578-592.

NMFS (U.S. National Marine Fisheries Service). 2006. Final consolidated Atlantic highly migratory species fishery management plan. U.S. National Marine Fisheries Service, Silver Spring, Maryland.

NMFS (U.S. National Marine Fisheries Service). 2013. Massachusetts recreational Bluefin Tuna landings census pilot-final report. Available: https://www.st.nmfs.noaa.gov/mdms/public/finalReport.jsp?ReportID= 710. (May 2014).

NMFS (U.S. National Marine Fisheries Service). 2017. 2016 stock assessment and fishery evaluation (SAFE) report for Atlantic highly migratory species. U.S. National Marine Fisheries Service, Silver Spring, Maryland.

NOAA (National Oceanic and Atmospheric Administration). 2001. Atlantic highly migratory species (HMS); Atlantic tunas reporting, fishery allocations and regulatory adjustments. Federal Register 66:158(15 August 2001):42801-42805.

NOAA (National Oceanic and Atmospheric Administration). 2002. Atlantic highly migratory species (HMS) fishing vessel permits; charter boat operations. Federal Register 67:243(18 December 2002): 77434-77439.

NOAA (National Oceanic and Atmospheric Administration). 2003. Atlantic highly migratory species; Bluefin Tuna catch limit adjustments. Federal Register 68:116(17 June 2003):35822-35824.

NOAA (National Oceanic and Atmospheric Administration). 2006. Atlantic highly migratory species; recreational Atlantic Blue and White marlin landings limit; amendments to the fishery management plan for Atlantic tunas, swordfish, and sharks and the fishery management plan of Atlantic billfish. Federal Register 71:190(2 October 2006):58058-58174.

NOAA (National Oceanic and Atmospheric Administration). 2009. Atlantic highly migratory species; 2009 Atlantic Bluefin Tuna quota specifications and effort controls. Federal Register 74:103(1 June 2009):26110-26117.

NOAA (National Oceanic and Atmospheric Administration). 2010. Atlantic highly migratory species; Atlantic Bluefin Tuna fisheries. Federal Register 75:113(14 June 2010):33531-33533.
NOAA (National Oceanic and Atmospheric Administration). 2011. Atlantic highly migratory species; Atlantic Bluefin Tuna fisheries. Federal Register 76:64(4 April 2011):18416-18418.

NOAA (National Oceanic and Atmospheric Administration). 2012. Atlantic highly migratory species; Atlantic Bluefin Tuna fisheries. Federal Register 77:68(9 April 2012):21015-21017.

NOAA (National Oceanic and Atmospheric Administration). 2014a. Atlantic highly migratory species; Atlantic Bluefin Tuna fisheries. Federal Register 79:87(6 May 2014):25707-25709.

NOAA (National Oceanic and Atmospheric Administration). 2014b. Atlantic highly migratory species; 2006 consolidated Atlantic highly migratory species (HMS) fishery management plan; amendment 7. Federal Register 79:231(2 December 2014):71510-71608.

NOAA (National Oceanic and Atmospheric Administration). 2017. Atlantic highly migratory species; Atlantic Bluefin Tuna fisheries. Federal Register 82:81(28 April 2017):19615-19618.

Oh, C., R. B. Ditton, B. Gentner, and R. Riechers. 2005. A stated preference choice approach to understanding angler preferences for management options. Human Dimensions of Wildlife 10:173-186.

Olsen, S. B. 2009. Choosing between internet and mail survey modes for choice experiment surveys considering non-market goods. Environmental and Resource Economics 44:591-610.

Orbach, M. K. 1980. The human dimension. Pages 149-163 in R. T. Lackey and L. A. Nielsen, editors. Fisheries management. Wiley, New York.

Park, T., J. B. Loomis, and M. Creel. 1991. Confidence intervals for evaluating benefits estimates from dichotomous choice contingent valuation studies. Land Economics 67:64-73.

Provencher, B., K. A. Baerenklau, and R. C. Bishop. 2002. A finite mixture logit model of recreational angling with serially correlated random utility. American Journal of Agricultural Economics 84:10661075.

R Core Team. 2016. R: a language and environment for statistical computing. R Foundation for Statistical Computing, Vienna.

Schuhmann, P. W. 1996. A welfare analysis of commercial fishery harvest restrictions: a bioeconomic model of Red Drum stock dynamics and recreation demand. Doctoral dissertation. North Carolina State University, Raleigh.

Shih, T.-H., and X. Fan. 2008. Comparing response rates from web and mail surveys: a meta-analysis. Field Methods 20:249-271.

Stokesbury, M. J. W., J. D. Neilson, E. Susko, and S. J. Cooke. 2011. Estimating mortality of Atlantic Bluefin Tuna (Thunnus thynnus) in an experimental recreational catch-and-release fishery. Biological Conservation 144:2684-2691.

Stoll, J. R., and R. B. Ditton. 2006. Understanding anglers' willingness to pay under alternative management regimes. Human Dimensions of Wildlife 11:27-42.

Sutton, S. G., and R. B. Ditton. 2001. Understanding catch-and-release behavior among U.S. Atlantic Bluefin Tuna anglers. Human Dimensions of Wildlife 6:49-66.

Train, K. E. 2009. Discrete choice methods with simulation, 2nd edition. Cambridge University Press, Cambridge, UK.

U.S. Office of the Federal Register. 2003. National standard 1-optimum yield. Code of Federal Regulations, Title 50, Chapter 6, Part 600, Section 600.310. U.S. Government Printing Office, Washington, D.C.

Voiland, M. P., and M. W. Duttweiler. 1984. Where's the humanity? A challenge and opportunity for the fisheries community. Fisheries 9 (4): $10-12$

Wallmo, K., and S. Edwards. 2008. Estimating non-market values of marine protected areas: a latent class modeling approach. Marine Resource Economics 23:301-323. 


\section{Appendix: Responses to Non-DCE Survey Questions}

Examination of non-DCE survey questions provided an initial framework for exploring angler attitudes and preferences to test in choice modeling efforts (Table A.1). For example, there appeared to be strong segmentation by region, with anglers from New England coastal states $(n=333)$ exhibiting distinct angling behaviors and preferences compared with those from the New York/New Jersey $(n=334)$ or mid-Atlantic (Delaware, Maryland, Virginia, and North Carolina; $n=313$ ) regions. New England anglers generally had higher incomes, targeted Bluefin Tuna more frequently (both in terms of trips per season and having targeted Bluefin Tuna in recent years), were less consumptively oriented, and targeted Bluefin Tuna closer to port than anglers from other regions. This apparent heterogeneity was used to inform individualspecific $Z$ variables to incorporate into the latent class model. While attitudes regarding the importance of harvest showed a high degree of variation among respondents, anglers appeared broadly willing to accept some degree of reduction in harvest if it meant increased fishery quality in future years: $78.3 \%$ of respondents agreed or strongly agreed with the statement, "I would be willing to accept a lower daily Bluefin Tuna bag limit if doing so would help further rebuild Bluefin Tuna stocks and allow for greater future fishing opportunities." At the same time, however, a majority of anglers (59.3\%) agreed or strongly agreed that they would never target Bluefin Tuna if they were not allowed to harvest fish.

TABLE A.1. Responses to non-DCE questions used to inform latent class choice modeling. Different lowercase letters indicate regional values that are significantly different from one another $(P=0.05)$. Only respondents who previously stated that they had targeted Bluefin Tuna in the last 5 years answered the question indicating how many trips they took in 2015 that targeted Bluefin Tuna.

\begin{tabular}{|c|c|c|c|c|c|}
\hline Variable & Description (sample size) & Value & $\begin{array}{l}\text { New } \\
\text { England }\end{array}$ & $\begin{array}{l}\text { New York/ } \\
\text { New Jersey }\end{array}$ & Mid-Atlantic \\
\hline Age & Mean age in years $(1,129)$ & 56 & & & \\
\hline Income & $\begin{array}{l}\% \text { with annual } \\
\text { income }>\$ 150,000(965)\end{array}$ & $37.8 \%$ & $41.9 \% \mathrm{z}$ & $41.3 \%$ & $30.4 \% \mathrm{y}$ \\
\hline Years targeting HMS & Mean in years $(1,111)$ & 14.7 & & & \\
\hline Bluefin Tuna targeting & $\begin{array}{l}\% \text { who have targeted } \\
\text { Bluefin Tuna in last } \\
5 \text { years }(1,143)\end{array}$ & $61.9 \%$ & $76 \% \mathrm{z}$ & $66.1 \% \mathrm{z}$ & $43.5 \% \mathrm{y}$ \\
\hline 2015 trips targeting Bluefin Tuna & $\begin{array}{l}\text { Mean in number of trips } \\
\text { (711) }\end{array}$ & 3.12 & $4.2 \mathrm{z}$ & $2.6 \mathrm{y}$ & $2.1 \mathrm{y}$ \\
\hline Distance from port fished & $\begin{array}{l}\% \text { who fished for Bluefin } \\
\text { Tuna }<25 \text { miles from } \\
\text { port }(686)\end{array}$ & $30.8 \%$ & $54.4 \% \mathrm{z}$ & $10.9 \% \mathrm{y}$ & $19.7 \% \mathrm{y}$ \\
\hline Voluntarily release Bluefin Tuna & $\begin{array}{l}\% \text { who ever voluntarily } \\
\text { released Bluefin Tuna } \\
(683)\end{array}$ & $51.4 \%$ & & & \\
\hline Consumptive orientation & $\begin{array}{l}\% \text { with consumptive } \\
\text { orientation }(670)\end{array}$ & $39.3 \%$ & $21.6 \% \mathrm{z}$ & $57.3 \% \mathrm{y}$ & $41.6 \% \mathrm{y}$ \\
\hline Season length preference & $\begin{array}{l}\% \text { who prefer short, high- } \\
\text { harvest season }(685)\end{array}$ & $38.8 \%$ & $22 \% \mathrm{z}$ & $53 \% \mathrm{y}$ & $46.8 \% \mathrm{y}$ \\
\hline
\end{tabular}


TABLE A.2. Percent (\%) of individuals in each class (absolute class assignment) who exhibit specific individual characteristics. A single asterisk (*) denotes a significant difference in percentage between classes at $P=0.05$; a double asterisk $(* *)$ denotes significance at $P=0.01$. For the consumptive and nonconsumptive orientation variables, sample size only includes those in each class who had targeted Bluefin Tuna in the last 5 years $(n=412$ for class 1,255 for class 2 ).

\begin{tabular}{llcc}
\hline Variable & \multicolumn{1}{c}{ Description } & Class 1 $(n=523)$ & Class 2 $(n=457)$ \\
\hline Target Bluefin Tuna & \% who have targeted Bluefin Tuna in last 5 years & $78.8^{* *}$ & $55.7^{* *}$ \\
New England & \% New England permit holders & 36.7 & 30.9 \\
New York/New Jersey & \% New York/New Jersey permit holders & 35.6 & 32.4 \\
Mid-Atlantic & \% mid-Atlantic permit holders & $27.7^{*}$ & $37.0^{*}$ \\
Consumptive orientation & \% with consumptive orientation & 35.2 & 37.3 \\
Nonconsumptive orientation & \% with nonconsumptive orientation & 33 & 28.2 \\
High income & \% with annual income $>\$ 150,000$ & $38.1^{*}$ & $28.6^{*}$ \\
\hline
\end{tabular}

